\title{
Megacystis Microcolon Intestinal Hypoperistalsis Syndrome-A Rare Case
} Saurabh Tiwari ${ }^{1 *}$, Paras Kothari ${ }^{2}$, Apoorva Kulkarni ${ }^{3}$, Abhaya Gupta ${ }^{4}$

\footnotetext{
${ }^{1}$ 3rd Year MCH Pediatric Surgery Resident, Department of Pediatric Surgery, R. No 440, LTMMC \& GH, Sion, Mumbai 400022, India

${ }^{2}$ Professor and Head of Department, Department of Pediatric Surgery, R. No 440, LTMMC \& GH, Sion, Mumbai 400022, India

${ }^{3}$ Senior Registrar, Department of Pediatric Surgery, R. No 440, LTMMC \& GH, Sion, Mumbai 400022, India

${ }^{4}$ Associate Professor, Department of Pediatric Surgery, R. No 440, LTMMC \& GH, Sion, Mumbai 400022, India
}

DOI: $10.36347 /$ sjmcr.2020.v08i06.006

| Received: 08.06.2020 | Accepted: 16.06.2020 | Published: 18.06.2020

*Corresponding author: Saurabh Tiwari

Abstract

Case Report

Megacystis Microcolon Intestinal Hypoperistalsis Syndrome (MMIHS) is a quite rare congenital and fatal disease which was firstly defined by Berdon and colleagues in 1976 [1] and is often underdiagnosed and confused with other disorders. The clinicians priority is to be make a correct diagnosis. It predominantly affects females (4:1 ratio) and is characterized by the presence of distended bladder (without distal urinary tract obstruction), microcolon, and decreased or absent intestinal peristalsis. We present a case of female newborn with antenatal ultrasound revealing a large cystic mass in pelvis of urinary tract origin, abdominal distension, aperistalsis of the intestine and micro colon. Gastrostomy and vesicostomy was done. Pathological findings of small bowel biopsy revealed normal ganglion cells. Child died of septicaemia at age of 20 days.

Keywords: Megacystis, microcolon, hypoperistalsis, Berdon syndrome.

Copyright @ 2020: This is an open-access article distributed under the terms of the Creative Commons Attribution license which permits unrestricted use, distribution, and reproduction in any medium for non-commercial use (NonCommercial, or CC-BY-NC) provided the original author and source are credited.

\section{INTRODUCTION}

227 cases of MMIHS were reported in literature up to 2011 with a female predominance of $2-$ 4:1 [2]. The etiology and pathogenesis of the disease are not clear. However, many hypothesis have been proposed such as degenerative disease of smooth muscle, disturbance in bowel innervation [3, 4], imbalance of gut peptides, in utero intramural inflammatory process of gastrointestinal and urinary tract, defect of contractile fiber synthesis and drugs. Most cases are sporadic while some have autosomal recessive inheritance. The earliest time to detect distended urinary bladder and hydronephrosis was at 16-20 weeks [5]. Although there is no specific findings for MMIHS, pathological studies of the colon, small intestine and urinary bladder are important for differentiating from other diseases The most important ultrasonographic finding is distended urinary bladder without oligohydramnios which is different from obstructive uropathy diseases. MMIHS is a fatal disease, and most patients die within one year after birth due to severe sepsis, renal failure, liver failure, malnutrition and complication of TPN. Treatment is supportive. We report a case of MMIHS with typical manifestations in a newborn.

\section{Case Report}

3 Day old $2.1 \mathrm{~kg}$ female child born of full term normal delivery brought with complaints of not passed meconium since birth with moderate abdominal distension. There was no history of fever, vomiting, respiratory distress. Child had passed urine on the first day of life. Antenatal scan at 29 weeks-7.4* $6.1 \mathrm{~cm}$ pelvic cystic lesion with over distended bladder with bilateral pevicalyceal dilatation $8 \mathrm{~mm}$. Abdominal examination revealed moderate abdominal distension with fullness in lower abdomen with decreased bowel sounds. Other examinations such as the head, neck, chest, limbs, spine, perineum and genitalia were normal. $\mathrm{Hb}$ was $10.8 \mathrm{~g} / \mathrm{dl}$ with normal electrolytes, urea13 and creatinine of 0.9 .

Postnatal ultrasound revealed bilateral moderate to gross hydronephrosis with distended bladder with bowel loops in lower abdomen of normal caliber and rectum undilated. Child was catheterized and nasogastric tube was inserted. Negligible amount of meconium was seen by rectal tube insertion. Xray abdomen suggestive of? Jejunoileal atresia (Figure-1). Barium enema was suggestive of microcolon (Figure2). Based on radiological studies a provisional diagnosis of MMIHS was made. Patient was posted for exploratory laparotomy. Small bowel from mid-jejunum upto colon \& rectum was small in calibre. Huge size 
collapsed urinary bladder reaching upto epigastrium (Figure-3). Other organs were normal. Gastrostomy with blocksom's vesicostomy was done. Dye study from GT after 3 days suggested retailed dye in stomach. Total parenteral nutrition was advised to the parents but they took discharge against medical advise. Finally the patient died due to renal failure and severe electrolytes imbalance, and dehydration and septicaemia.

Histopathology of small bowel biopsy revealed thinned muscle with ganglion cells.

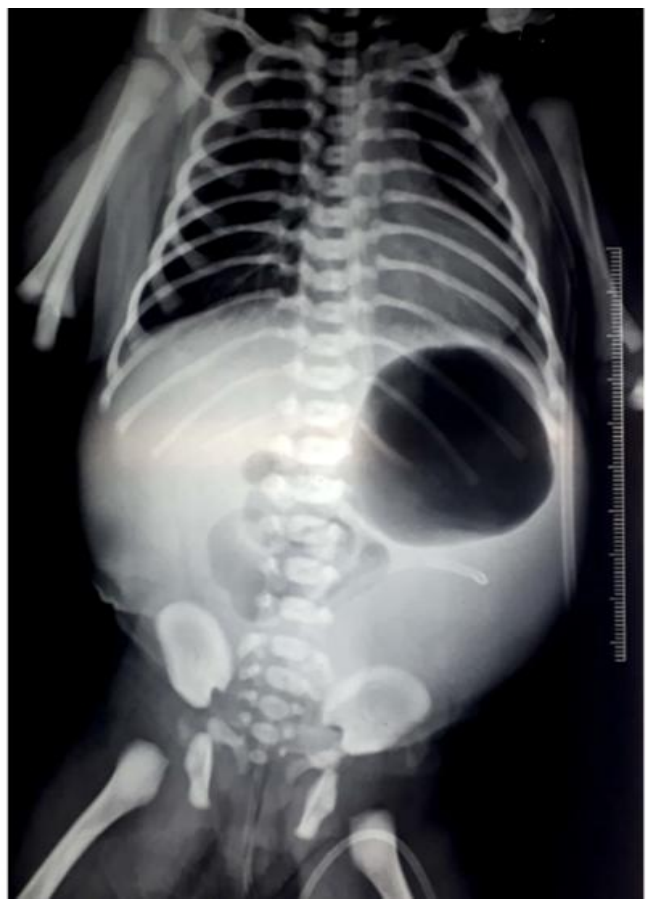

Fig-1: Barium enema suggestive of microcolon

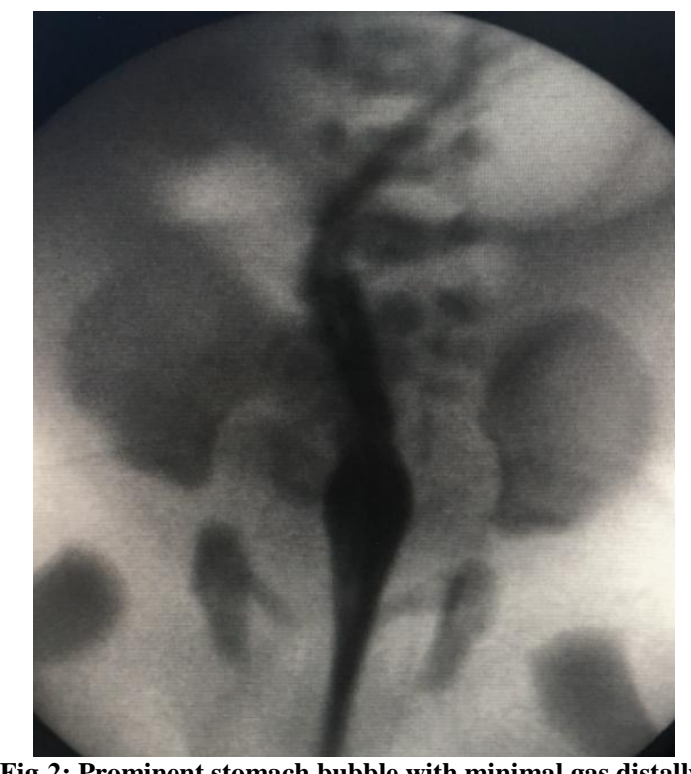

Fig-2: Prominent stomach bubble with minimal gas distally

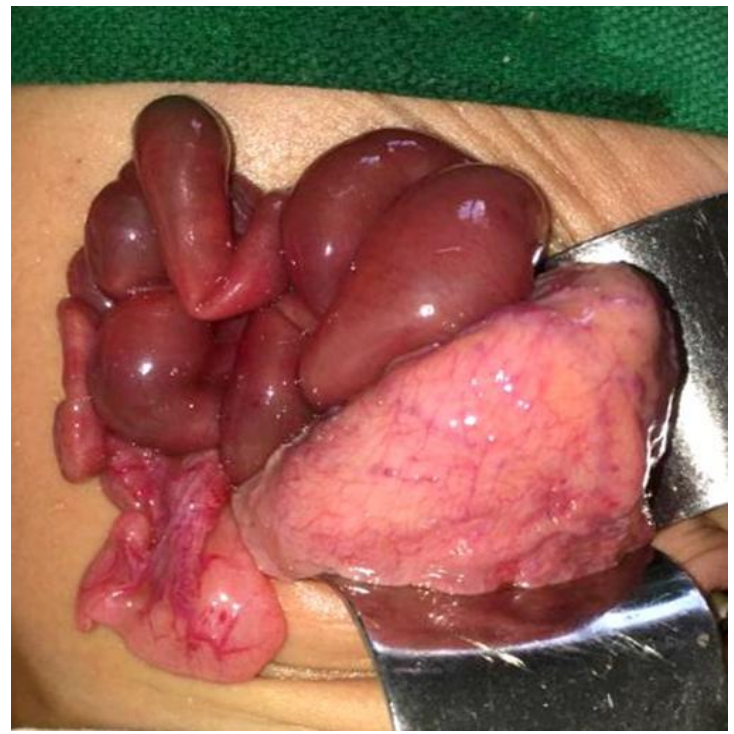

Fig-3: Megacystis with microcolon

\section{DISCUSSION}

Chronic intestinal pseudo-obstruction is a disorder characterized by persistent failure of the intestine to propel its contents through an unobstructed lumen. MMIHS is characterized with hypoperistalsis or aperistalsis of gastrointestinal system, nonobstructive bladder distension, malrotation, dilated proximal ileum, and colon [6]. Differential diagnosis can be prune belly syndrome, urethral agenesis, intestinal atresia, volvulus and total colon agangliosis.

Other secondary causes of ileus or pseudoobstruction such as hypothyroidism, hypokalemia and narcotics must be excluded.

Pathological findings of gastrointestinal tract are varied. Most important finding of MMIHS is normal or increased ganglion cells [7] which is different from total aganglionosis. Other accompanying anomalies include omphalocele, cardiac malformations, rhabdomyoma and intestinal malformation [8]. Nutritional support is the mainstay of treatment. Hyperalimentation is required.

Surgical treatment choices are limited, and an eff ective surgical method has not been defined yet. Prokinetic drugs and gastrointestinal hormones for promoting bowel motility are ineffective. Raofi et al., believed that multi organ transplantation is the only way to rescue these patients [9]. Intermittent bladder catheterization and antibiotics are most feasible therapeutic option for urological management.

\section{Conclusion}

Prenatal diagnosis of MMIHS is possible by antenatal ultrasound. MRI appears useful for diagnosing microcolon associated with an enlarged bladder, suggesting MMIHS. Antenatal USG finding of an enlarged urinary bladder and intraabdominal mass in 
female fetus should alert the physicians for MMIHS. Clinical genetic counselling is indicated for further pregnancies.

\section{Source(s) of Support: Nil \\ Presentation at a Meeting: Nil \\ Conflicting Interest: Nil}

\section{REFERENCES}

1. Berdon WE, Baker DH, Blanc WA, Gay B, Santulli TV, Donovan C. Megacystis-microcolonintestinal hypoperistalsis syndrome: a new cause of intestinal obstruction in the newborn. Report of radiologic findings in five newborn girls. American Journal of Roentgenology. 1976 May 1;126(5):957-64.

2. Gosemann JH, Puri P. Megacystis microcolon intestinal hypoperistalsis syndrome: systematic review of outcome. Pediatr Surg Int, 2011;27:1041-6.

3. Kubota M, Ikeda K, Ito Y. Autonomic innervation of the intestine from a baby with megacystis microcolon intestinal hypoperistalsis syndrome: II. Electrophysiological study. J Pediatr Surg, 1989; 24: 1267-70.

4. Kirtane J, Talwalker V, Dastur DK. Megacystis, microcolon, intestinal hypoperistalsis syndrome: possible pathogenesis. J Pediatr Surg, 1984; 19: 206-8.

5. Carlsson SA, Hokegard KH, Mattsson LA. Megacystis-microcolon-intestinal hypoperistalsis syndrome. Antenatal appearance in two cases. Acta Obstet Gynecol Scand, 1992; 71:645-8.

6. Loinaz C, Rodríguez MM, Kato T, Mittal N, Romaguera RL, Bruce JH, Nishida S, Levi D, Madariaga J, Tzakis AG. Intestinal and multivisceral transplantation in children with severe gastrointestinal dysmotility. Journal of pediatric surgery. 2005 Oct 1;40(10):1598-604.

7. Kupferman JC, Stewart CL, Schapfel DM, Kaskel FJ, Fine RN. Megacystis-microcolon-intestinal hypoperistalsis syndrome. Pediatr Nephrol, 1995; 9: 626-7.

8. Mantan M, Singhal KK, Sethi GR, Aggarwal SK. Megacystis, microcolon, intestinal hypoperistalsis syndrome and bilateral streak gonads. Indian journal of nephrology. $2011 \mathrm{Jul} ; 21(3): 212-4$.

9. Raofi V, Beatty E, Testa G, Abcarian H, Oberholzer J, Sankary H, Grevious M, Benedetti E. Combined living-related segmental liver and bowel transplantation for megacystis-microcolonintestinal hypoperistalsis syndrome. Journal of pediatric surgery. 2008 Feb 1;43(2):e9-11. 